\title{
Open Research Online
}

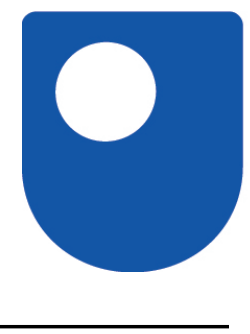

The Open University's repository of research publications and other research outputs

\section{A Farrier Making Every Contact Count: A Microlevel Analysis of Farrier-Client Interaction for Partnership Working in Managing a Horse With Laminitis}

\section{Journal Item}

How to cite:

Lynden, Jenny; Hollands, Teresa and Ogden, Jane (2020). A Farrier Making Every Contact Count: A Microlevel Analysis of Farrier-Client Interaction for Partnership Working in Managing a Horse With Laminitis. Journal of Equine Veterinary Science, 87, article no. 102924.

For guidance on citations see $\underline{\text { FAQs }}$

(C) 2020 Elsevier Inc.

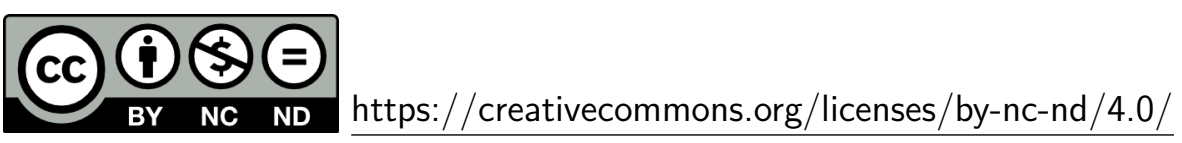

Version: Accepted Manuscript

Link(s) to article on publisher's website:

http://dx.doi.org/doi:10.1016/j.jevs.2020.102924

Copyright and Moral Rights for the articles on this site are retained by the individual authors and/or other copyright owners. For more information on Open Research Online's data policy on reuse of materials please consult the policies page.

\section{oro.open.ac.uk}


A farrier making every contact count: a microlevel analysis of farrier-client interaction for partnership working in managing a horse with laminitis

Abstract

There is an evidence-base in human and small animal veterinary healthcare contexts which understands how practitioners engage in partnership working with patients and owners to support adherence to treatment/care plans. However, as yet, it is believed there is no similar evidence-base for how practitioners in equine healthcare contexts work with equine owners. It is argued that this is essential for understanding complex equine practitioner-owner interaction involving the prevention and management of laminitis. The aim of this study was to explore farrier-client interaction where risk management for an equine recovering from laminitis was being undertaken. A case report method involved a microlevel analysis of farrier-client consultation. The consultation was video-recorded and analysed using a conversation analysis approach to identify the linguistic and paralinguistic features of the interaction. These were compared with conversation analyses in other healthcare contexts to identify the actions being accomplished within the consultation. The analysis identified a number of joint actions, including managing epistemic stance (or knowledge rights) and deploying the animal's presence to navigate problem sequences which supported progression of the consultation through a three-stage model involving 'team-', 'option-' and 'decision-' talk, known to be associated with partnership working in human healthcare contexts. The study highlights the importance of developing an empirical evidence-base in equine practice for how practitioners engage with owners based on a microlevel analysis of real-world interactions. It is argued this evidence-base is necessary in supporting effective practitioner training in partnership working with clients to promote their adherence to treatment/care plans. 
Keywords: farriers; partnership working; laminitis; conversation analysis; equine

Glossary of key terms for a microlevel analysis of interaction and communication

\begin{tabular}{|c|c|}
\hline Affiliation display & $\begin{array}{l}\text { Features in interaction which display support for the other party's } \\
\text { account of their experience and/or feelings. }\end{array}$ \\
\hline $\begin{array}{l}\text { Conversation } \\
\text { analysis }(C A)\end{array}$ & $\begin{array}{l}\text { An approach which studies interaction to understand how verbal and } \\
\text { nonverbal communication accomplishes action between people. In } \\
\text { particular, conversation analysis uses an approach called 'next turn } \\
\text { proof procedure' which systematically identifies patterns of } \\
\text { communication in turn-taking across many different similar } \\
\text { interactions. The analysis is used to develop theories about how } \\
\text { people express and respond to emotion, manage problematic } \\
\text { communication, engage with each other collaboratively, as well as } \\
\text { many other actions in everyday contexts. }\end{array}$ \\
\hline Epistemic stance & $\begin{array}{l}\text { Epistemic stance concerns how people assert their right to claim } \\
\text { 'expertise' on a particular topic and how this is responded to by the } \\
\text { other party. It is expressed in 'moment-by-moment' turn-taking in } \\
\text { which both parties work to jointly negotiate their right to possess and } \\
\text { articulate knowledge. While a dynamic process, at any moment in } \\
\text { time one party is likely to occupy more of a K+ position (i.e. } \\
\text { demonstrate their 'expertise' on the matter in hand), while the other } \\
\text { party is more likely to occupy a K- position (i.e. indicating more } \\
\text { limited claims to knowledge). }\end{array}$ \\
\hline Latching & $\begin{array}{l}\text { Usually in a conversation there are very short pauses between two } \\
\text { speakers' turns. However, sometimes 'latching' occurs. This is } \\
\text { when there is no disenable pause between turn-taking. This type of } \\
\text { interaction can demonstrate collaboration between two speakers (e.g. } \\
\text { joint story telling). }\end{array}$ \\
\hline $\begin{array}{l}\text { Linguistic } \\
\text { communication }\end{array}$ & A type of communication that conveys meaning through language. \\
\hline $\begin{array}{l}\text { Jeffersonian } \\
\text { transcription } \\
\text { system }\end{array}$ & $\begin{array}{l}\text { A system of transcription notation which is used to transcribe } \\
\text { interactions for conversation analysis. It involves a fine-grained } \\
\text { representation of linguistic and paralinguistic communication. }\end{array}$ \\
\hline $\begin{array}{l}\text { Next turn proof } \\
\text { procedure }\end{array}$ & $\begin{array}{l}\text { A procedure which seeks to systematically identify communication } \\
\text { patterns across similar interactions to understand how action is } \\
\text { achieved between two or more parties. }\end{array}$ \\
\hline NVivo & $\begin{array}{l}\text { A computer-assisted qualitative data analysis software programme } \\
\text { which supports a sophisticated analysis of multimodal data. }\end{array}$ \\
\hline $\begin{array}{l}\text { Paralinguistic } \\
\text { communication }\end{array}$ & $\begin{array}{l}\text { A type of communication that conveys meaning through audible } \\
\text { sounds which are not words. This would include, for example, } \\
\text { changes in pitch or tone, volume, pacing and pauses. }\end{array}$ \\
\hline
\end{tabular}




\begin{tabular}{|l|l|}
\hline $\begin{array}{l}\text { Roter Interaction } \\
\text { Analysis System } \\
\text { (RIAS) }\end{array}$ & $\begin{array}{l}\text { A method for 'coding' dialogue between two or more parties, where } \\
\text { each utterance is assigned to pre-define categories. They can then be } \\
\text { grouped into 'socio-emotional/affective communication or } \\
\text { instrumental communication. }\end{array}$ \\
\hline $\begin{array}{l}\text { Socio- } \\
\text { emotional/affective } \\
\text { communication }\end{array}$ & $\begin{array}{l}\text { A type of communication which supports relationship building } \\
\text { through the development of rapport and trust between two or more } \\
\text { parties. }\end{array}$ \\
\hline $\begin{array}{l}\text { Social institution } \\
\text { This refers to any group which shares common values, expectations } \\
\text { and understandings to achieve a common purpose. }\end{array}$ \\
\hline
\end{tabular}

34 


\section{$1 \quad$ Introduction}

Effective communication in equine veterinary healthcare contexts is recognised as being pivotal in supporting effective diagnosis, patnership working, client adherence to treatment/care plans and in reducing veterinarian stress and client complaints [1]. For example, some equine vets have proposed a '4E model' which is described as involving engagement, empathy, education and enlisting owners as partners for effective team working [2]. This approach, it is aruged, is crucial when working with owners to prevent and manage laminitis, where treatment/care plans are complex and likely to result in signficant changes to equine diet, turnout and exercise routines [3]. In this context, it is recongised that farriers are also an essential part of the team, working closely with both veterinarians and owners when managing horses with laminitis [4]. While farriers have reported using complex communication strategies for joint problem solving when working with owners to support the prevention and management of laminitis [5], there has been no microlevel analysis of farrierclient interaction.

In human healthcare contexts, there is a long-established evidence-base to understand how practitioners can engage effectively with clients to support problem-solving and behaviour change. Studies have focused on how open-ended questioning techniques, associated with a person-centred approach, support clients to explore their beliefs, attitudes and behaviour, and can have efficacy in supporting behaviour change [6]. Similarly, there has been a significant shift in communication approaches within small animal veterinary contexts with a greater focus on developing a partnership approach with owners to support them to engage with and adhere to treatment/care plans [7]. This has mainly been developed from process analysis 
small animal practice [8] and focuses on how socio-emotional/affective communication can lead to joint problem-solving, higher levels of client adherence and satisfaction [9].

However, to the authors' knowledge, there is no empirical evidence-base, using real-world interactional data, for how conversations with clients are structured in lamintis care contexts, and whether they have efficacy for: (i) eliciting information from owners; (ii) engaging owners in problem-solving, or (iii) fostering client adherence to treatment/care plans. Given the important role of farriers in supporting equine veterinarians in managing equine recovery from laminitis, the aim of this study was to explore a farrier-client interaction where risk management was being undertaken for a horse recovering from laminitis using a microlevel analysis.

\section{Materials and methods}

\subsection{Design}

A case report method was adopted to identify how farrier-client interactions were being managed because, as argued by Yin [10], a case report method can address explanatory, rather than just descriptive or exploratory research questions, and because it enables in-depth analysis of a relevant case example in its real-world context. In this study, a case was sought which involved a holistically-focused farrier working with welfare-focused owners with a horse that had laminitis. While a single case report cannot be generalised to wider populations, it does have the power to be generalisable to 'theoretical propositions' [10] and is useful in identifying specific interactional features within a care setting [11]. This case report design aimed to identify whether any of the features within the farrier-client consultation could be analytically generalised to existing communication theory regarding 
practitioner-client interaction and what types of actions might be being facilitated by both parties.

\subsection{Participants}

A farrier (Matthew) ${ }^{1}$, who had participanted in a former study [5] and was identified as a 'holistically-focused' farrier because of his account of his day-to-day working practices with clients, was invited to participate in this study and asked if he could nominate an owner whose equine had had laminitis and was due to consult with him. Matthew identified two owners whose horse, Raffles, was recovering from laminitis. The owners were reported by Matthew to be welfare-focused, and had been working with their vet and Matthew for a number of months to support Raffles' recovery from laminitis. This case was selected on the basis that it would be 'revelatory' [10] of how a holistically-focused farrier worked with welfare-focused owners so as to identify how this type of interaction was managed.

\subsection{Participant profiles}

Matthew had higher level farriery qualifications and had practised in England, UK for over 20 years. He was a specialist remedial farrier who received veterinary referrals. His clients, Mary and Peter owned two equines, one of whom was Raffles. Raffles was an older equine who had been diagnosed with acute laminitis for the first time several months earlier. Raffles was housed on a private yard. Matthew had worked closely with Mary and Peter, as well as their equine vet to support the development of a treatment/care plan to aid Raffles' recovery. The treatment/care plan included veterinary interventions, remedial farriery, a managed diet and box rest. At the time of the consultation, radiographs had been taken of Raffles' hooves and the vet had suggested that she was ready for some managed turnout and exercise.

\footnotetext{
${ }^{1}$ Pseudonyms have been assigned to all participants to preserve participant confidentiality.
} 
Matthew was on a routine farriery visit where he discussed next steps in Raffles' rehabilitation. Mary and Peter were concerned that giving Raffles more turnout might cause harm and undermine their work in getting Raffles to her current stage of recovery.

\subsection{Procedure}

The study received favourable ethical opinion from the University Ethics Committee at the University of Surrey. All participants were given information sheets and signed a consent form. They were invited to ask questions and advised that they could withdraw from the study at any stage. The recording equipment, set up prior to the horse being brought into the shoeing bay, comprised an audio and small video cameras camoflaged in hessian bags securely tied to tie up rings.

\subsubsection{Analytic strategy}

The study used a conversation analysis approach, which involves a microlevel anlaysis focusing on the linguistic and the paralinguistic features of interaction. In particular, this approach uses 'next turn proof procedure'. This procedure seeks to systematically identify patterns across different interactions to understand how action is achieved [12]. While most CA studies would aim to collect many examples of similar interactions to identify patterns of action within that context, there is a developing interest in using a case report method which focuses on just one interaction to identify its communicative features and compare these existing CA theory which has been derived from the analysis of a large corpora of data [11].

An audio recording of the consultation which lasted for 1 hour and 5 minutes, was transcribed to include all spoken language in NVivo, which had the advantage of synchronising the transcript with the recordings. This strategy facilitated the first stage of a 
CA approach which involved listening to the audio recording and reading through the transcript noting interesting interactions which did not presuppose 'analytic goals', but rather involved 'noticings' of what might initially be considered as 'unremarkable features of talk', but which served to reveal action being accomplished [13]. Sequences were identified which involved: 'problem definition and exploration', 'rapport building', 'collaboration' and 'challenge'.

These sequences were selected for a second 'layer' of transcription using a simplified version of Jeffersonian transcription conventions [14] (see Figure 1). This involved transcribing and integrating some of the paralinguistic interaction which was deemed relevant to the action being accomplished. This included, for example, when each individual's 'turn' began, pauses, laughter, speech overlaps and latching (where no natural pauses occur between speaker turns). Additionally, summary descriptions were made of non-verbal interaction between the participants, also as they were deemed relevant to the action being accomplished, which is recommended for a CA of face-to-face interaction [15].

The second stage of the CA approach involved identifying analytic generalisations by comparing features within the sequences selected in stage two of the analysis with the CA literature regarding what these features are believed to accomplish. This had the advantage of matching patterns within the interaction in the current study with those based on largescale empirical CA studies where action accomplishment is based on 'next turn proof procedure' [12]. The credibility of the analysis was tested through data sessions with the second $[\mathrm{TH}]$ and third [JO] authors, and through presenting the data analysis at a data session on 25th July 2018 at the Nuffield Department of Primary Care Health Sciences at Oxford 
159

University. The session involved repeatedly playing the recordings and reviewing the transcripts with a team of healthcare communication specialists.

[Figure 1 about here]

\section{Results}

This analysis focuses on how Matthew can be seen to support his clients, Mary and Peter, through a consultation involving a 'three-talk' model [16]. This began with all parties engaging in 'team talk' to explore the 'problem' by identifying Raffles' readiness to move on to the next phase in her rehabilitation. This was followed by 'option talk' to explore posibilities for managed turnout and, finally, 'decision-talk' to agree goals for achieving this. Two joint actions were identified (i) managing epistemic stance (or knowledge rights) [17] and power relations within the interaction; and (ii) deploying the animal's presence to navigate problem sequences [18] were identified. These served to support successful navigation through the stages of the three-talk model (see Figure 2).

[Figure 2 about here]

\subsection{Stage 1: 'Team talk'}

The consultation began by Matthew asking an open-ended question (Line 1) and using a reflective listening technique (Line 4) which led to an exploration of Mary's and Peter's perception of Raffles' stage of recovery and their concerns regarding giving her more turnout (Lines 7-25).

1. Matthew: so how's she been (...) generally then would you say (...) 
2. ((Matthew attending to hoof with his back to Mary))

3. Mary: she's been fine

4. Matthew: yes she's been fine

5. ((moves to another hoof, Mary looks at Matthew, Matthew makes eye contact with

6. Mary and then looks back to horse))

7. Mary: she enjoys coming out here=

8. Matthew: =right that's good

9. ((Matthew looks at Mary))

10. Mary: than standing (.)

11. Matthew: yeah (...)

12. ((Matthew attends to another hoof))

13. Mary: she hasn't been out quite as long as (.) since the foot's been around but

14. ((Client bends down to look at what the Matthew is doing))

15. Matthew: right (laughs) (...) what's the foot's disturbing her and stuff=

16. Mary: =well yeah it's just sort of it getting (...) trodden on really

17. Matthew: (...) (laughs) well (laughs) (inaudible) (...)

18. Peter: how long is she out Mary when she's out here=

19. ((Peter standing behind horse and out of view))

20. Mary: $=$ she's been $=$

21. Peter: $=$ of a morning $=$

22. Mary: =I've had her out (.) usually from about 10 til lunchtime (...)

23. ((Matthew looks at Mary and takes a long breath in and out, places his hands on his

24. hips))

25. Matthew: right 
196

In the next sequence of the consultation Matthew can be seen to position Mary as having expert knowledge with regard to Raffles' stage of recovery. From a CA perspective, Matthew achieves this by managing epistemic stance. Epistemic stance concerns the positioning of participants within the interaction with regard to their claims to knowledge rights. It is expressed in 'moment-by-moment' 'turns-at-talk' in which both parties work to jointly recognise their right to 'possess' and 'articulate' knowledge [19]. While a dynamic process, at any moment in time one party is likely to occupy a $\mathrm{K}+$ position, and thereby demonstrate their 'expertise' on the matter in hand, while the other party occupies a Kposition, indicating more limited claims to knowledge rights [20].

During the 'team talk' stage, Mary can be seen to offer Matthew a K+ (expert) position regarding Raffles' readiness to be given more turnout and exercise than she had (Line 26).

26. Mary: but I haven't taken her any further so should we be taking her further 27. ((Mary looks at Matthew))

It is interesting that Matthew's response was not to take up a $\mathrm{K}+$ position, but rather to use a question sequence and adopt passive body language (e.g. looking down at the floor) which served to place him in a K- position. This can be seen to successfully repositioned Mary as having K+ knowledge rights to Raffles' readiness for more turnout and exercise (Lines 2839).

28. Matthew: $\quad$ urhm well (...)

29. ((Matthew looks away from Mary towards horse's back foot, hand gesture continues to lean on broom handle)) 
30. I don't know I mean [I]

31. (Matthew looks down at the floor))

32. Mary: [ri] $[\mathrm{ght}]$

33. Matthew: [I I] was just asking you really if (.) urhm if she looked like she was kin[da]

34. Peter: [yea] [h ]

35. Matthew: [wa]nting to go a little bit further (...) urhnm because that would

36. kinda of I suppose indicate $=$

37. ((Matthew looks at Mary and uses hand and face gestures, continues to lean on

38. broom handle))

39. Mary: =that's she's ready to [move]

This shows Matthew's preparedness to adopt a facilitative rather than a directive approach, which served to legitimise his clients' 'expertise' on Raffles' condition and thereby secured them the opportunity to consider a wider range of causes for Raffles' stiffness and whether the advantages of increased turnout could outweigh the risks. The next sequence demonstrates the success of this strategy in that the turn-taking sequences can be seen as indicating a high level of mutual collaboration between Matthew and his clients. This is because it involves 'latching' when there are no audible gaps, recognised in CA as showing an 'affiliation display' through collaborative turn completion [21] (Lines 40-65).

40. Matthew: she was (.) err (...) she looked stiffer than when she was going in=

41. Peter: $=$ yeah $=$

42. ((Matthew looks at Peter))

43. Mary: =yeah she's sort of hopping (.) I can only describe it as (...) you're not 
44. wanting to put on a lot a lot of weight on the left hind and you'd think it would be

45. the other one (.) that she wouldn't want to but (...)

46. Matthew: y[eah]

47. Mary: [she's] picking that up very quickly (...) and sort of hopping round the

48. corner but because she didn't do it this morning because you're here $=$

49. ((Mary looks to Peter and then back to Matthew, moves to illustrate how horse

50. moves, looks and points to horse's hind foot and looks back to Matthew))

51. ((Matthew looks at Mary and then to where she is pointing))

52. Matthew: $=$ no (laughs) $=$

53. ((Matthew looks at Mary))

54. Mary: $=$ that's typical (laughs) $=$

55. Peter: $=$ she's not done it [every]

56. ((Matthew looks at Peter))

57. Mary: [no not] every day=

58. Matthew: $=$ no=

59. Peter: =day it's intermittent isn't it and we do sometimes wonder if it's because

60. she's been more or less in one position for $($.$) in the stable =$

61. ((Matthew looks at Peter uses hand gesture moves backwards and leans on freezer))

62. Mary: =yeah be[cause]

63. Matthew: [this is]=

64. Peter: $=$ this is your point really about $=$

65. Matthew: $=$ yeah yeah= 
Here one might have expected Matthew to use Peter's statement (Line 64) as an opportunity

to begin planning for change. However, in the next sequence Matthew choses to pause instead (Line 66) which provided space for Mary to express concern (Lines 67-87).

66. Matthew: hmmm (...)

67. Mary: [but I wouldn't want to do any harm]

68. ((Client looks towards Matthew $))$

69. Peter: if it's only four or [five feet]

70. Mary: [you see]=

71. Matthew: $=$ no, no, no, no=

72. ((Matthew looks at Mary and then away towards the horse's back foot and then

73. back to Mary))

74. Mary: =having got to=

75. Matthew: $=\mathrm{no}=$

76. Mary: = having got her to her sort of standing comfort[tably]

77. ((Mary looking from Matthew to horse and using hand gestures))

78. Matthew:

79. Mary: and she's not lying down a lot like she [was]

80. Matthew: [no ]

81. Mary: when you think [about]

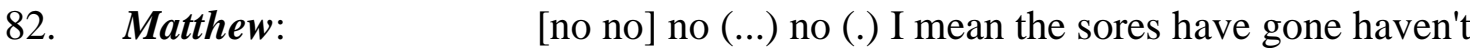

83. they and things like that (...)

84. ((Matthew looks towards Mary and Peter moves closer to the Matthew and Mary,

85. strokes horse))

86. Mary: there's no red sores I think she is putting a little bit of weight on (...) she's

87. not looking quite as (.) angular I don't think as she did 
88. ((Mary looks at horse; Matthew looks at horse; Peter is stroking horse))

217

218

It is interesting to see Matthew used the speech token 'no no no no' in Lines 71 and 82.

Strivers argues that these types of 'multiple sayings' are deployed by speakers to signal that they are 'dealing with an entire course of action and not only the "just prior unit" of talk [22].

Here the use of this utterance by Matthew served not to contradict Mary's assessment of Raffles' vulnerability, but rather to attend to it and to suggest that Mary had successfully safeguarded Raffles' well-being and successful recovery, which validated Mary's point of view and suggested Raffles may be in a position to begin the next stage of recovery. This supported progression of the consultation towards 'option talk'.

\subsection{Stage 2: 'Option Talk'}

A little later in the consultation, Matthew could be seen to guide the consultation towards 'option talk' by refocusing the conversation on to Raffles' recovery, shown in the next sequence (Lines 89-108).

89. Matthew :...urhm (.) but you know (.) also looking at (.) kinda ways of

90. urhm (...) you know (...) helping you manage her and help her with her

91. rehabilitation $=$

92. ((Matthew looks towards Mary, then towards the horse, Mary looks at Matthew, Peter looks at the horse))

93. Mary: $[=\mathrm{mmmm}=]$

94. Peter: $[=\mathrm{mmmm}=]$

95. (Peter looks towards Matthew and then back at horse))

96. Matthew: urhmm so (...) urhmm (...) you know that that's why I was kinda asking 


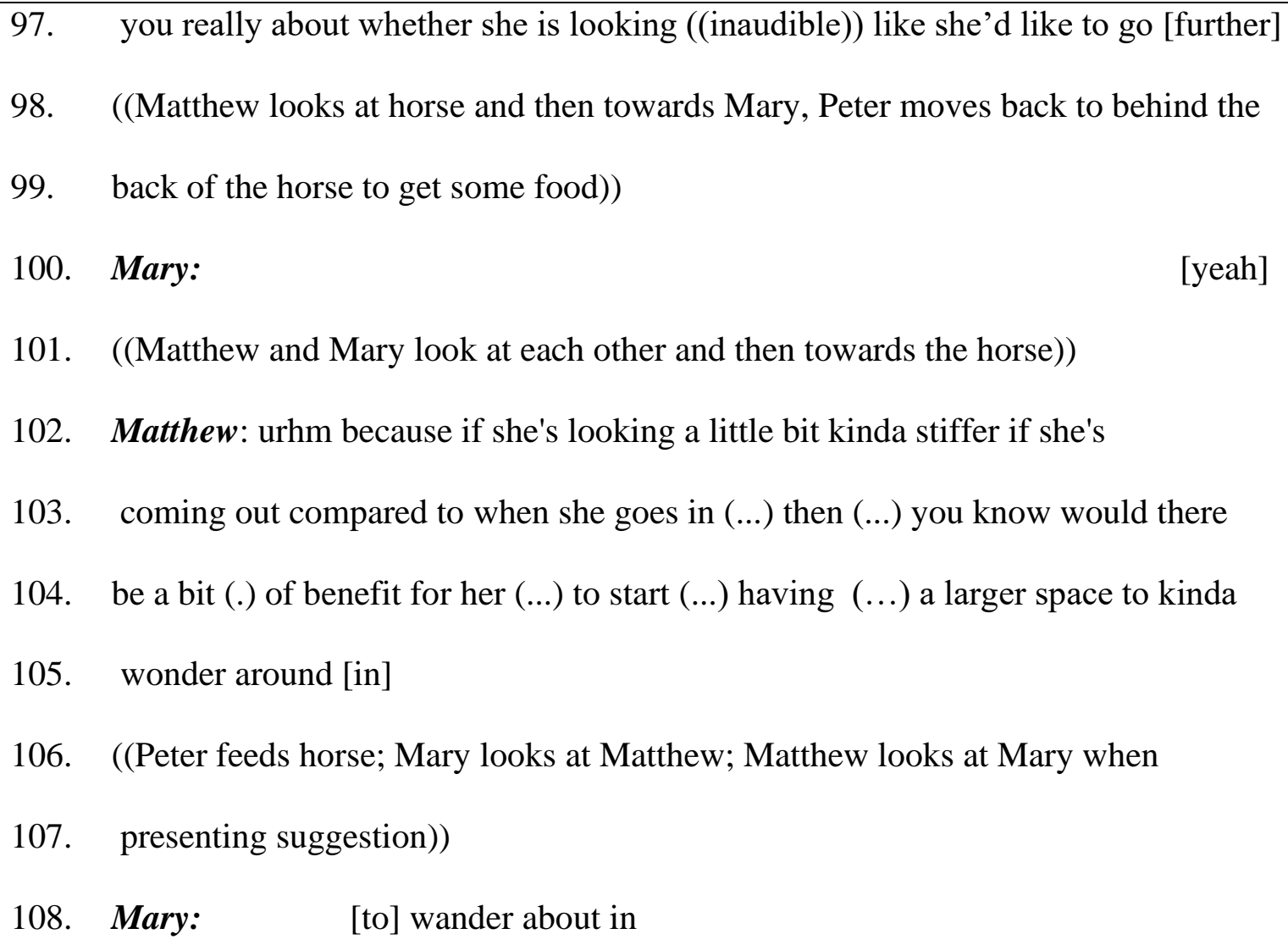

233 It is interesting to note that during this second stage Matthew was seen to work hard to continue to build rapport and trust by recognising Mary's and Peter's expertise in their knowledge of what was best for Raffles. It is also interesting to note that Matthew referred to Raffles' preference when exploring options for increased turnout. It is now recognised in small animal practice that veterinarians deploy the animal's presence by speaking to and on behalf of the animal being presented for consultation in order to 'avert professionally (and socially) risky activities' associated with challenging or confronting the client [18]. It was interesting, therefore, that Matthew invoked Raffles' presence within the consultation (Lines: 109-124).

109. Matthew: has she has she looked like she's wanted to (.) go any further (...) or 110. ((Matthew briefly looks away and then back to Mary, uses hand gestures)) 
111. Mary: yes occasionally she's wanted to come up here hasn't she=

112. ((Mary looks to Peter and then to Matthew))

113. Matthew : =right (...) but not necessarily (...) thought about

114. ((Matthew looks directly at client, leans on broom handle))

115. Matthew: I (.) I was just asking you really if (...) urhm (...) if she looked like she

116. was kinda w[anting]

117. ((Matthew looks at Mary and uses hand and face gestures, continues to lean on

118. broom handle))

119. Peter: [yeah]

120. Matthew: to go a little bit further urhm because that would kinda of I suppose

121. indicate $=$

122. Mary: =that's she's ready to move $=$

123. Matthew: =you know how comfortable she is really=

124. Mary: $=\mathrm{yeah}=$

This sequence demonstrated how Matthew invoked the horse's presence by 'articulating'

Raffles' willingness and ability to move as an indicator that she was ready for the next stage of rehabilitation. This may, in part, have successfully navigated the consultation to the next stage involving decision-making.

\subsection{Stage 3: 'Decision-talk'}

The final stage of the consultation involved Matthew supporting his clients in their decisionmaking regarding how they give Raffles more space for exercise. The opening of this sequence clearly highlighted Matthew's move to encourage Mary and Peter to begin 
decision-making for changing Raffles' environment to provide more turnout and exercise (Lines 125-132).

255

125. Matthew: yeah I mean I I I was I was just wondering about you know whether

126. either out there [or ]

127. ((Matthew standing at the side of horse, Mary and Peter at front of horse looking

128. towards the Matthew))

129. Peter: [ye]ah

130. Mary: [ye]ah

131. Matthew: or out at the back you could clear obstacles back

132. Peter: yeah

257 Additionally, all three parties were seen to invoke Raffles' presence and articulate her preferences to support their decision-making process in designing increased space for turnout and exercise (Lines: 133-144):

133. Matthew: $=$ so she had (...)

134. Mary: enough room to turn=

135. Matthew: =yeah enough space to turn around to move around mooch around

136. ((Matthew pets horse))

137. Peter: as she wanted to $=$

138. Matthew: $=$ as she wanted to=

139. Peter: $=$ as she felt confident enough to $=$

140. Matthew: $=$ exactly 
141. Peter: $\mathrm{mmmm}$

142. Matthew: and and let her=

143. Mary: $=$ decide $=$

144. Matthew: =decide how much kinda exercise she wants to do

This approach for deploying the animal's presence facilitated problem-solving because it seemed to reassure Mary and Peter that by initiating this change they were unlikely to do harm to Raffles as she has been given agency to decide for herself what was in her best interests. It could be argued that it is, in part, supported Mary and Peter to engage in jointaction planning to begin the next phase of Raffles' rehabilitation (Lines 145-161).

145. Peter: I think I mean the disadvantage with the front is it's

146. not level=

147. ((Peter looks at Mary, Mary calls horse towards her))

148. Matthew: =it's not level [yeah]

149. Mary: [yeah]

150. Peter: and it's closer to him

151. Mary: yeah

152. Peter: and I'd just be a bit concerned you know cos=

153. ((Peter looks towards Matthew and uses hand gestures))

154. Mary: =they're at war

155. Peter: urhm so from that point of view I think the back (...) is going to be

156. better than this because there's some distance I think be[tween ]

157. ((Peter points towards the back of the barn, and looks towards Mary))
158. Mary:
[and its level] $=$ 
159. Peter: =between Casper and (.) and because it's level yeah (...) I think we could do 160. something out [there]

161. Mary: [yeah ] I think so...

269 The remainder of the consultation focused on action planning. At the end of the consultation Matthew requested permission to feedback their action plan to his clients' equine vet for which Mary and Peter consented.

\section{Discussion}

This study aimed to explore farrier-client interaction where laminitis risk management was his farriery practice, engaged in this process. The analysis demonstrated how one farrier, who was working closely with an equine veterinarian, used complex communication strategies to support his clients to explore a problem related to the care of their horse. In particular, it illustrated how the farrier was able to engage both clients in exploring their concerns, as well as their options for moving their horse on to the next stage of rehabilitation.

This illustrated how a three-talk model for communication, recognised as important for shared decision-making and increasing patient adherence in human healthcare settings [16], can be adopted in an equine care context. In particular, the farrier-client interaction in this study has demonstrated how a farrier used a facilitative rather than directive approach throughout the consultation. This was achieved through the use of open-ended questions and reflective listening techniques which served to privilege the expertise of the clients, rather than impose his own expert knowledge by giving advice and guidance. This analysis provides evidence for how effective this technique can be in supporting owners to adapt their 
care practices in order to support the ongoing rehabilitation of their horse recovering from laminitis.

The current study provides evidence which supports the analysis from a study which presented farrier and owner reports of how farriers use complex communication strategies to engage their clients in exploring problems and solutions when managing laminitis risk and supporting equine rehabilitation [5]. Many farriers were reported as giving specific examples of how they used open-ended questions to explore their client's perspectives and concerns, necessary to explore solutions in innovative ways given the resources available to clients. As can be seen from the evidence presented in this study, making arrangements for increasing managed turnout depended upon securing the clients' agreement that this was the best course of action for a laminitic horse they were deeply attached to and had nursed for several months. Additionally, identifying a solution for appropriate turnout which was dry and secure, in a location where no manège was available, required joint farrier-client problemsolving.

It is clear from the evidence presented in this case report that farriers can adopt a facilitative style of communication which is associated with client-centred techniques. This style of communication avoids confrontation and supports clients through the joint exploration of their beliefs, attitudes and goals as a foundation in supporting behaviour change [6]. By adopting a CA approach, this study has shown the particular techniques that can be employed by farriers when working with their clients. It was interesting, for example, to identify the sequences in which the farrier resisted being positioned as an 'expert' when offered a $\mathrm{K}+$ position by the clients. A farrier adopting a more directive approach might have been expected to accept this positioning by offering expert advice and guidance. However, in this 
case report, the farrier declined an expert role at that point in the consultation, thereby facilitating his clients to explore their own evidence-base to assess for themselves the readiness of their horse to undertake the next stage of its rehabilitation. This demonstrates how 'epistemic stance' [19] can be managed very successfully by farriers in equine care contexts. Additionally, the farrier in this study 'invoked' the animal's presence to manage problem sequences [18], in particular, by attributing 'agency' to the horse in order to help his clients overcome their anxiety about doing her harm.

It is believed that this is the first study which involves a microlevel analysis using real-world interaction data in an equine care context. As noted in the introduction, while there are some models advocated by equine vets for adopting a facilitative approach when consulting with clients [2] and particularly when equines are diagnosed with laminitis [23], this study illustrates how these types of facilitative approaches can be accomplished in equine care settings. While this case report focused on farrier-client, rather than veterinary-client communication, it demonstrates the importance of using video-recorded data for a microlevel analysis in understanding the features of effective communication in equine care contexts. As Mondada [15] argues, it is essential to analyse recordings of naturally occurring social interaction to describe the organisation of social activities and action being accomplished through turn-taking. While it could be argued the recording equipment may have led to demand characteristics with participants behaving in inauthentic ways, when participants were debriefed they all reported 'forgetting the cameras were there' because they were inconspicuous. The participants also claimed that the consultation represented their normal interaction during a farriery consultation. The validity of this analysis was strengthened through analytic generalisation to CA theories for similar patterns in other health and veterinary care contexts. This utilises a robust validation criterion in CA which involves 
what Hutchby and Wooffitt [12] identify as the 'next turn proof procedure'. This requires the identification of recognisable linguistic and paralinguistic patterns within interaction across a large corpus of data. The reliability of the analytic generalisations from the current study to existing CA theory was further strengthened because the data and the initial analysis, developed by the authors, were presented at a data session at Oxford University.

However, the current study is limited in that the analysis cannot be generalised to a wider farrier population. While this case report design has provided a detailed account of how action is being accomplished through interaction in a farrier-client consultation, it is impossible to identify the extent to which farriers, more generally, adopt some or all of these communication strategies. As Arminen [24] states, conversational styles will vary across different social institutions and while comparative analysis, across institutions, is useful in identifying more general features of how action is being achieved, it does not have the capacity to identify the unique and specific interactional patterns within a social institution. Evidence of interactions across a very large number of farrier and equine vet consultations would be needed to identify the unique variations in communication in practice and what types of actions these achieve. A larger study would also justify a much finer-grained and indepth analysis using full Jeffersonian transcription conventions than was possible in the current study.

\section{Conclusion}

Notwithstanding the limitations identified here, the current study has identified important communication strategies which farriers, vets and other equine practitioners could use in their interactions with clients to engage them in partnership working. It highlights the importance of developing an evidence-base for how practitioners engage with their clients and also for 
practitioner training to recognise and work with both the linguistic and paralinguistic features of communication to support effective partnership working with clients and to support adherence to treatment/care plans.

\section{References}

[1] McDermott, M.P., Tischler, V.A., Cobb, M.A., Robbé, I.J. and Dean, R.S. (2015) Veterinarianclient communication skills: current state, relevance, and opportunities for improvement. Journal of veterinary medical education 42, 305-314.

[2] Bonvicini, K.A. (2006) Tools for enhancing communication: an overview of risk management in equine practice. In: Proceedings. 52nd Annual American Association of Equine Practitioners Convention pp 181-187.

[3] Johnson, P.J., Wiedmeyer, C.E., LaCarrubba, A., Ganjam, V.S. and Messer, N.T. (2010) Laminitis and the equine metabolic syndrome. Veterinary Clinics of North America: Equine Practice 26, 239-255.

[4] Moyer, W., Werner, H., O'Grady, S. and Ridley, J. (2018) The veterinary-farrier relationship. Equine Veterinary Education 30, 573-575.

[5] Lynden, J., Ogden, J. and Hollands, T. (2018) Contracting for care-the construction of the farrier role in supporting horse owners to prevent laminitis. Equine veterinary journal 50, 658-666.

[6] Miller, W.R. and Rollnick, S. (2012) Motivational interviewing: Helping people change, Guilford press, New York.

[7] Gray, C. and Moffett, J. (2013) Handbook of veterinary communication skills, John Wiley \& Sons, West Sussex.

[8] Roter, D. and Larson, S. (2002) The Roter interaction analysis system (RIAS): utility and flexibility for analysis of medical interactions. Patient Education and Counseling 46, 243-251.

[9] Kanji, N., Coe, J.B., Adams, C.L. and Shaw, J.R. (2012) Effect of veterinarian-client-patient interactions on client adherence to dentistry and surgery recommendations in companionanimal practice. Journal of the American Veterinary Medical Association 240, 427-436.

[10] Yin, R.K. (2017) Case study research and applications: Design and methods, Sage publications, London. 
[11] Chatwin, J. (2014) Conversation analysis as a method for investigating interaction in care home environments. Dementia 13, 737-746.

[12] Hutchby, I. and Wooffitt, R. (1998) Conversation Analysis: Principles, practice and applications. Cambridge, England: Polity.

[13] Have, P. (1999) Doing conversation analysis: a practical guide, Sage Publications, London; Thousand Oaks, Calif.

[14] Hepburn, A. and Bolden, G.B. (2013) The conversation analytic approach to transcription. In: The Handbook of Conversation Analysis, Ed: J. Sidnell, \& Stivers, T., John Wiley \& Sons Ltd., West Sussex. pp 57-76.

[15] Mondada, L. (2012) The conversation analytic approach to data collection. In: The Handbook of Conversation Analysis, Ed: J. Sidnell, \& Stivers, T. , John Wiley \& Sons. pp 32-56.

[16] Elwyn, G., Durand, M.A., Song, J., Aarts, J., Barr, P.J., Berger, Z., Cochran, N., Frosch, D., Galasiński, D. and Gulbrandsen, P. (2017) A three-talk model for shared decision making: multistage consultation process. British Medical Journal 359, 1-7.

[17] Heritage, J. (2012) The epistemic engine: Sequence organization and territories of knowledge. Research on Language and Social Interaction 45, 30-52.

[18] Roberts, F. (2004) Speaking to and for animals in a veterinary clinic: A practice for managing interpersonal interaction. Research on Language and Social Interaction 37, 421-446.

[19] Heritage, J. (2012) Epistemics in action: Action formation and territories of knowledge. Research on Language and Social Interaction 45, 1-29.

[20] Heritage, J. (2013) Action formation and its epistemic (and other) backgrounds. Discourse Studies 15, 551-578.

[21] Lerner, G.H. (1991) On the syntax of sentences-in-progress. Language in Society 20, 441-458.

[22] Stivers, A. (2004) "No no no" and other types of multiple sayings in social interaction. Human Communication Research 30, 260-293.

[23] Walsh, D.M. (2004) Laminitis: what to tell the owner. Clinical Techniques in Equine Practice 3, 83-87.

[24] Arminen, I. (2005) Institutional interaction : studies of talk at work, Ashgate Pub, Aldershot, Hants, England; Burlington, VT. 
PARTNERSHIP WORKING

447

448 
4497 Acknowledgements

450 The authors would like to thank the farrier and horse owner participants for their interest in 451 the study and their time in engaging with the observation. We would also like to thank the

452 team at the Nuffield Department of Primary Care Health Sciences at Oxford University, and 453 in particular, Charlotte Albury, for such valuable feedback during a data session.

454

455

\section{$456 \quad 8 \quad$ Funding}

457 This research did not receive any specific grant from funding agencies in the public, 458 commercial, or not-for-profit sectors.

459

460 